\section{Looking to the future and learning lessons from the recent past: changing stakeholder perceptions of biosimilars in} cancer

\author{
Won Seog Kim, ${ }^{*, 1}$ Michinori Ogura² ${ }^{2}$ Hyuk-Chan Kwon³ \& Dasom Choi ${ }^{3}$
}

As the patents for many biologic anticancer drugs expire, significant growth in the use of biosimilars is predicted, offering an opportunity to help combat the rising costs of treatment and increase patient access to biologic therapy. Attainment of regulatory approval, involving numerous nonclinical and clinical comparative studies versus each reference product, is only one of several barriers to realize the potential gains offered by biosimilars. It is important to understand the current perceptions and informational needs of different stakeholders if biosimilars are to be accepted and widely used in the clinic. We discuss these considerations and refer to recent experiences with CT-P13, a biosimilar of the TNF inhibitor infliximab used to treat rheumatoid arthritis and other inflammatory disorders.

First draft submitted: 30 March 2017; Accepted for publication: 20 April 2017; Published online: 9 May 2017

Biologic drugs are integral, albeit high-cost, components of the treatment pathway for many different types of cancer. Patent protection of these drugs began to be issued in the late 1990s and now, as many of these patents expire, significant growth in the use of lower cost biosimilars is predicted [1]. This new era of biosimilar anticancer drugs, which started with the recent approval of the rituximab biosimilar CT-P10 (Truxima ${ }^{\circledR}$; CELLTRION, Incheon, Republic of Korea) in South Korea and then in Europe [2], offers an opportunity to help combat the rising costs of cancer treatment. The introduction of these new biosimilars may also increase the number of patients accessing biologic therapies, permit access to these therapies at earlier stages of disease (if appropriate) and/or allow funding of novel biologic drugs or other new treatments. The opportunities for biosimilar cancer therapeutics to positively impact the treatment landscape are therefore manifold. By contrast, concerns over biosimilars frequently focus on the unknown safety issues surrounding the inevitable differences that exist between a biosimilar and its reference product, and also the appropriate naming conventions that should be used to distinguish biosimilar drugs. Similarly, extrapolation across indications, interchangeability and automatic substitution are not yet universally understood concepts [3].

Well-defined regulatory requirements ensure that any biosimilar approved by the EMA or the FDA (or by other licensing bodies adopting similar biosimilar approval pathways) will have undergone rigorous evaluations and comparisons with its reference product [4]. Notably, criteria for the licensing of biosimilars are markedly different from those for generic drugs, which usually only include proof of product quality and bioequivalence with the reference product $[5,6]$. In contrast, approval pathways for biosimilars involve detailed and direct comparisons of a

'Sungkyunkwan University School of Medicine, Samsung Medical Center, Seoul, Republic of Korea

2Department of Hematology, Tokai Central Hospital, Gifu, Kakamigahara, Japan

${ }^{3}$ CELLTRION Healthcare Co. Ltd, Incheon, Republic of Korea

*Author for correspondence: Tel.: +82 234106 548; Fax:+ 82234101 757; wskimsmc@skku.edu

\section{KEYWORDS}

- biosimilars $\bullet$ CT-P10

- CT-P13 • infliximab

- oncology $\bullet$ rituximab 
candidate biosimilar and its reference product in analytical in vitro, nonclinical in vivo and clinical studies [7-11]. The extent of clinical data that is required for approval of a biosimilar is dependent on a number of factors, including the degree of residual uncertainty regarding biosimilarity following the preceding analyses. However, typically clinical data must be sufficient to demonstrate statistical equivalence of the biosimilar and reference product in terms of pharmacokinetics and efficacy, and also demonstrate comparable safety and immunogenicity profiles $[4,7,11]$. Attainment of regulatory approval is, however, only one of several barriers to be overcome before the potential gains offered by biosimilars can be fully realized. For biosimilars to be fully accepted as valid treatment options, and thus more widely used in clinic, it is important to understand the current perceptions and informational needs of different stakeholders - including physicians, pharmacists, payers, nurses and patients - with respect to biosimilars and biosimilarity.

In this article, we aim to summarize currently available evidence regarding current perceptions of biosimilars held by key stakeholders in cancer treatment. We also consider how stakeholder education and the filling of guideline and informational gaps could help trigger an evolution in these perceptions, increase confidence in biosimilars, and ensure their effective and safe use. In the final part of the article, we discuss these considerations with reference to CT-P13, a biosimilar of the TNF inhibitor infliximab that has now become an established option for the treatment of rheumatoid arthritis (RA) and other immune-mediated inflammatory disorders in Europe.

Current perceptions of biosimilars among cancer treatment stakeholders

- Physician perceptions

Cost is undoubtedly a key factor that will drive the uptake of new biosimilars among physicians who care for patients with cancer. In a survey of hematologists and oncologists from the USA and four emerging markets performed between July and August 2013, only 39\% of respondents considered rituximab to be easy to access from a cost perspective. Over half (52\%) stated they would increase their use of rituximab in patients with non-Hodgkin's lymphoma or chronic lymphocytic leukemia if a biosimilar priced at $70 \%$ of the reference product price was available [12]. In another survey carried out in the same countries in December 2012 and January 2013, 45\% of oncologists stated that they would increase use of HER2-targeted therapy for treating HER2-positive breast cancer if a lower cost biosimilar of trastuzumab was available [13]. Among those who stated that they would not increase the use of such therapy, the most commonly cited reason was that they "already always use it in all the appropriate patients/situations" [13]. Also in the solid tumor setting, a recently published survey of oncologists in the USA, Europe and three emerging markets reported that around $50 \%$ of respondents would 'probably' or 'definitely" prescribe a bevacizumab biosimilar [14], with lower cost being cited as a factor that would increase the likelihood of respondents prescribing such a biosimilar. In a survey of US physicians in specialties where biologic drugs are commonly used (including oncology), 83\% said that they would prescribe a biosimilar if it were $25 \%$ less costly than the originator drug, compared with $33 \%$ if the biosimilar were only $5 \%$ less expensive [15].

Other factors influencing the likelihood of a physician prescribing biosimilars are the availability of efficacy and safety data on these drugs [14,15]. A notable proportion of physicians question the safety of biosimilars. In a survey performed in the USA from November 2015 to January 2016, 50\% of medical oncologists and $43 \%$ of hematologist-oncologists disagreed with the proposal that biosimilars will be safe for use in treatment-naive and already-treated patients [16]. Notably, 34 and 29\%, respectively, of these specialty physicians believed that biosimilars will be less safe than their reference products due to the abbreviated regulatory pathway for biosimilar approval [16]. This misconception may stem from a lack of awareness regarding the stringent regulatory criteria that must be met in order to prove biosimilarity. The same US survey, respondents to which also included other specialty physicians who regularly prescribe biologic drugs (e.g., gastroenterologists and rheumatologists), identified five major 'knowledge gaps' that should be addressed by evidence-based education on biosimilars: defining biologics, biosimilars and biosimilarity; understanding the approval process and the totality of evidence concept for biosimilar evaluation; understanding that the safety and immunogenicity of an approved 
biosimilar are comparable with those of the reference product; understanding the rationale for indication extrapolation; and defining interchangeability and rules on pharmacy-level substitution. Of note, only $12 \%$ of physicians surveyed were comfortable with indication extrapolation (i.e., approval of a biosimilar in indications held by the reference product without clinical studies in all of those indications [17]), emphasizing a particular need for education on this pivotal, and scientifically justified, biosimilar concept [16]. Other surveys provide insights into physicians' perceptions regarding the naming and labeling of biologic drugs. In a recent US survey, $68 \%$ of respondents believed that the FDA should require a distinct nonproprietary name for every biological product, whether originator or biosimilar, and $77 \%$ thought a manufacturer-specific suffix should be added to the name [18]. These findings are consistent with earlier US and EU physician surveys $[19,20]$.

Table 1 lists the recognized definitions for several terms related to biosimilars that are used in this article and have been identified by physicians as having the potential to cause confusion.

\section{- Pharmacist perceptions}

Current knowledge of pharmacist perceptions of biosimilars is based on a handful of published surveys [27-29]. The most recent that we identified was an online survey completed by the members of Academy of Managed Care Pharmacy and the Hematology/Oncology Pharmacy Association in the USA between May and June 2015. The aims of the survey included determining respondents' perceptions of biosimilar naming conventions. Participants reported that they were more confident in prescribing biosimilar products that shared the same nonproprietary name as the reference biologic. $33 \%$ of pharmacists surveyed were 'very confident' in prescribing a biosimilar that had the same nonproprietary name as the reference biologic, compared with $24 \%$ of participants when a unique brand name was used for the biosimilar. Use of the same nonproprietary name plus a suffix was the second most popular naming option, with $57 \%$ of participants being moderately or very confident at prescribing a biosimilar named in this manner. Reporting requirements also affected the likelihood of a pharmacist dispensing a biosimilar. $28 \%$ of participants stated that they would be less likely to prescribe a biosimilar if they were required to provide a postdispensing notification, with $23 \%$ of participants perceiving this requirement to be a substantial professional burden [27]. Similar findings were reported in an earlier survey by the Academy of Managed Care Pharmacy, the American Pharmacists Association and the American Society of Health-System Pharmacists [28]. Responses indicated that dispensing pharmacists may be influenced in their decision to substitute interchangeable biosimilars by the name of the product; the majority $(75 \%)$ of respondents were most confident with prescribing a biosimilar with the same nonproprietary name as the branded biologic, while only $25 \%$ would confidently prescribe a biosimilar with a different nonproprietary name [28]. Conversely, in a survey of hospital and retail pharmacists, most (68\%) thought that the FDA should stipulate that every biologic product (originator or biosimilar) should have a distinct nonproprietary name [30]. A further, small electronic survey of hospital and managed care pharmacists, which was reported in 2012, identified significant questions/concerns relating to the bioequivalence, safety and efficacy of biosimilars. More than $60 \%$ of institutional pharmacists believed that switching or cross-over trials would be needed to prove interchangeability of a drug. In addition, respondents wanted more information relating to the type and amount of clinical trial data needed for biosimilar approval, as well as technical information on comparability exercises [29].

\section{- Payer perceptions}

The lower cost of biosimilars makes these agents generally attractive to payers. In an online survey of payer perspectives performed in seven EU countries, Russia and the USA, the cost difference between a biosimilar and its reference product was cited as the most important factor in payer decision-making by all survey respondents [31]. The same survey identified oncology and immunology as the most desirable areas for biosimilar market penetration. Exploratory qualitative research involving payers from France, Germany, Italy, Netherlands, Spain and the UK found that these stakeholders do not expect biosimilars to offer savings of the magnitude seen with generic drugs as they understand that development of biosimilars is more complex and costly [32]. This research also showed that payers 
Table 1. Biosimilar-related terms and definitions.

\begin{tabular}{|c|c|c|}
\hline Term & Definition & Ref. \\
\hline Bioequivalence & $\begin{array}{l}\text { Two medicinal products containing the same active substance are considered bioequivalent if they are } \\
\text { pharmaceutically equivalent or pharmaceutical alternatives, and their bioavailabilities (rate and extent } \\
\text { of absorption) after administration in the same molar dose lie within acceptable predefined limits }\end{array}$ & [6] \\
\hline Biological medicine & A medicinal product with one or more active substances made or derived from a biological source & {$[21]$} \\
\hline Biosimilar & $\begin{array}{l}\text { A biological medicine that contains a version of the active substance of an already licensed original } \\
\text { biological medicinal product - the reference product }\end{array}$ & [7] \\
\hline Biosimilarity & $\begin{array}{l}\text { Property of a medicine to show similarity and lack of significant differences in terms of quality, efficacy } \\
\text { and safety to a reference biological medicine with which it has been compared }\end{array}$ & {$[22]$} \\
\hline Extrapolation & $\begin{array}{l}\text { Extending information and conclusions available from studies in one or more subgroups of the patient } \\
\text { population (source population) to make inferences for another subgroup of the population (target } \\
\text { population), or condition or product, thus reducing the need to generate additional information to reach } \\
\text { conclusions for the target population }\end{array}$ & {$[23]$} \\
\hline Generic & $\begin{array}{l}\text { A medicine that has the same composition in active substances and the same pharmaceutical form as } \\
\text { the originator reference medicinal product and whose bioequivalence with the reference medicinal } \\
\text { product has been demonstrated by appropriate bioequivalence studies }\end{array}$ & {$[22]$} \\
\hline INN & $\begin{array}{l}\text { International Non-proprietary Name; unique and universally recognized and accessible name of an } \\
\text { active substance; in other words, pharmaceutical substance or active pharmaceutical ingredient }\end{array}$ & [22] \\
\hline Interchangeability & $\begin{array}{l}\text { Medical/pharmaceutical practice of switching one medicine for another that is equivalent in a given } \\
\text { clinical setting. A product is considered to be interchangeable if it can be administered or dispensed } \\
\text { instead of another clinically equivalent product }\end{array}$ & {$[22]$} \\
\hline Reference product & $\begin{array}{l}\text { Originator medicinal product that has been granted marketing authorization and is used for the } \\
\text { comparability exercise during the development of a biosimilar or generic drug }\end{array}$ & [24] \\
\hline Substitution & $\begin{array}{l}\text { The practice of dispensing one medicine instead of another equivalent and interchangeable medicine at } \\
\text { the pharmacy level without requiring consultation with the prescriber }\end{array}$ & {$[22]$} \\
\hline Switching & $\begin{array}{l}\text { Decision by the treating physician to exchange one medicine for another medicine with the same } \\
\text { therapeutic intent (e.g., from originator to a generic/biosimilar or vice versa, or from biosimilar to } \\
\text { biosimilar) in a patient during the course of treatment }\end{array}$ & {$[25]$} \\
\hline Therapeutic equivalent & $\begin{array}{l}\text { A medicinal product is therapeutically equivalent with another if it contains the same active substance } \\
\text { or therapeutic moiety and, clinically, shows the same efficacy as that product, whose efficacy and safety } \\
\text { have previously been established }\end{array}$ & {$[26]$} \\
\hline
\end{tabular}

from the surveyed countries mainly defer to the EMA for decisions on the acceptability of indication extrapolation. While payers interviewed for the study were cognizant of physicians' concerns over the safety and efficacy of biosimilars (and are therefore unlikely to enforce substitution in patients currently treated with reference biologics), they are likely to recommend biosimilar use in treatment-naive patients [32]. Payers in the USA anticipate that biosimilars will provide a strategy to reduce the price of specialty drugs and most (88\% according to one survey) consider them a compelling business opportunity [33]. Key differences are predicted between US and European markets in terms of interchangeability and substitution at the pharmacy level. The FDA has the authority to designate a biosimilar as interchangeable with its reference product, such that a biosimilar may be substituted for the originator product by the pharmacist without reference to the prescribing physician, and has issued guidance for demonstrating interchangeability [34]. Conversely, in Europe, the EMA has issued no recommendations on interchangeability and has left the decision on this issue to each member country. Reflecting the increasing availability and use of biosimilars in clinical practice, payer-related bodies have begun to provide specific guidance on these drugs. For example, in January 2015, the UK National Institute for Health and Care Excellence issued a position statement stating that biosimilars will be considered in parallel with their reference products in their 'technology appraisals' on the use of medicines/treatments within the National Health Service [35]. 


\section{- Nurse perceptions}

A white paper on biosimilars produced by the US National Comprehensive Cancer Network, and based on a survey conducted at the 2011 National Comprehensive Cancer Network annual conference, recommended education on biosimilars for nurses and nurse practitioners, along with other healthcare practitioners and policy makers [36]. Of 71 nurse respondents, proportionally more nurses $(44 \%)$ than other healthcare providers said they were 'not at all familiar' with recent developments with biosimilars, and a third of nurses noted that they needed more information on them [36]. Nurses acknowledge that as biosimilars become more widely used as anticancer treatments, they need to know when a patient is receiving a biosimilar drug [37]. They also want to have a good understanding of development and regulatory steps for biosimilars so that they can continue to provide well-informed support and advice to patients [37].

\section{- Patient perceptions}

An international survey exploring attitudes and understanding about biosimilars among patients, caregivers and the general public found that awareness of biosimilars was low, with up to $70 \%$ of respondents having never heard of them [38]. Those who attended patient support groups were most likely to be aware of biosimilars as a treatment option, and those who did not know about this option were more likely to report positive perceptions of biosimilars. Respondents perceived reference products to be more safe and effective, although biosimilars were favored in terms of access and price [38]. A further survey conducted among elderly US patients also reported a lack of awareness of biosimilars; $92 \%$ of them did not know that a biosimilar could be used as a substitute for the originator drug, and 93\% were unaware that biosimilars are not exact copies of their originators [39].

\section{Establishing biosimilar cancer therapeutics in clinical practice}

To increase the uptake of biosimilars in clinical practice, and thus fully realize the opportunities offered by these new treatment options, the perceptions of some stakeholders will need to be challenged, and their educational and informational needs addressed. In this section, we consider how these goals may be achieved through a combination of education, continued data collection and the provision of guidance.

\section{- Education}

As described above, surveys have shown that many stakeholders, including a notable proportion of physicians and patients, have important knowledge gaps with respect to the 'basics of biosimilars.' Thus, the provision of effective and appropriately targeted education on the following key topics is essential for all stakeholders: definitions of biosimilars and biosimilarity; and biosimilar development pathways and how these permit proper, albeit nontraditional, evaluations of efficacy and safety.

Other educational efforts may be of high relevance for some stakeholders but not for others. For example, publications or other vehicles for disseminating the clinical data that led to the approval of a specific biosimilar are likely to be of particular interest to practicing physicians. On the other hand, payers may be more interested in data that quantify the potential socioeconomic impact of biosimilars. Both these audiences may benefit from education on relatively complex concepts such as indication extrapolation.

\section{- Continued data collection}

Although approval of a biosimilar under EMA, FDA or closely related biosimilar approval pathways denotes that biosimilarity with the reference product has been established, continued collection of data after regulatory approval is essential. This need arises not only from a pharmacovigilance perspective but also in terms of reassuring stakeholders about the efficacy, safety and pharmacoeconomic impact of biosimilars.

Postapproval data may arise from different sources, including the pharmacovigilance programs that are agreed between authorities such as the EMA and biosimilar license holders. These programs usually involve the monitoring of biosimilar safety and efficacy in 'real life' (i.e., in patients prescribed biosimilars as part of routine clinical care). However, they may also involve new clinical trials that are designed to address outstanding questions and allay stakeholder concerns (although such trials may also be performed outside of a pharmacovigilance program). For example, so-called 'switching studies' may be performed to evaluate whether the safety or efficacy of treatment is affected by switching from a reference product to its biosimilar drug, while other trials may directly compare the efficacy and safety of a biosimilar and its reference product in extrapolated indications. As for any new drug, the approval and introduction of a 
biosimilar into clinical practice may also be followed by the publication of physician-led 'realworld' evidence (e.g., case reports or observational studies). Collection of evidence regarding predicted/actual cost savings in budget impact, cost-effectiveness or other pharmacoeconomic analyses is of particular relevance for payers.

\section{- Incorporation into treatment guidelines/ medical society recommendations}

The incorporation of any new drug into wellrespected treatment guidelines is a potential indication of stakeholder acceptance, although the impact of this on the uptake of the new treatment will be heavily influenced by its position with these guidelines. Since the first biosimilar treatment for cancer has only recently been approved, no such drugs are captured within current treatment guidelines, although this is likely to change as these drugs become more established in clinical practice. In addition to treatment guidelines, biosimilars may also be discussed in different medical society recommendations or position statements. Of note, the European Society for Medical Oncology (ESMO) has recently issued a position statement which states that biosimilars "present a necessary and timely opportunity for physicians, patients and healthcare systems". This position statement also discusses issues surrounding biosimilars that ESMO considers relevant to the field of oncology, especially for prescribers (Table 2) [25].

\section{CT-P13: learnings from the first monoclonal antibody biosimilar}

In September 2013, CT-P13 (Remsima ${ }^{\circledR}$ [CELLTRION, Incheon, Republic of Korea] and Inflectra ${ }^{\circledR}$ [Pfizer, NY, USA]) was approved by the EMA for all indications held by reference infliximab, thus permitting the use of this second-generation biosimilar in RA, ankylosing spondylitis, psoriasis, psoriatic arthritis and inflammatory bowel disease (IBD; i.e., pediatric and adult Crohn's disease or ulcerative colitis). Uptake of CT-P13 has grown in many European countries since launch such that its market share - calculated as the number of CT-P13 vials sold as a percentage of the total number of reference product vials sold - ranged from 20 to $73 \%$ across five European countries by the end of the second quarter of 2016 (Figure 1) [40]. As CT-P13 was the first biosimilar to be licensed in its approved indications, and indeed was the first ever biosimilar monoclonal antibody to be approved by the EMA, this drug may provide a useful case study on how stakeholder acceptance can be achieved via education, continued data collection and provision of relevant guidance. Lessons learnt following the introduction of CT-P13 into clinical practice may be applied to other monoclonal antibody biosimilars postapproval. This may be particularly valuable for those intended for use in the treatment of cancer as there is currently a paucity of experience with these drugs to draw upon.

\section{- Education}

A key factor underlying the acceptance of CT-P13 as a treatment option by specialty physicians is likely to be improved postgraduate education. For example, an increase in education surrounding biosimilars was cited as one reason for the marked increase in confidence in prescribing biosimilars reported by IBD specialists in a survey reported in 2016, compared with a previous survey performed in 2013 [41]. Publication and wide dissemination of the data that led to approval of CT-P13 may also have increased acceptance of CT-P13 among physicians. The clinical studies of CT-P13 that were performed prior to approval (in patients with RA and ankylosing spondylitis) have been published in respected and well-read specialty journals [42-47].

For patients, improved confidence in biosimilars, including CT-P13, has been driven by the activity of different patient support groups. The Global Alliance for Patient Access [48] provides patient advocates, as well as physicians, with training and accessible information about developments in treatment, including biosimilars. In addition to providing relevant news updates and summaries of papers, the Global Alliance for Patient Access explains what the information means for patients. Support groups for patients with specific disorders, such as the UK National RA Society, also play a role in informing and educating patients. For example, the National RA Society position statement on biosimilars stresses the importance of patients' involvement in the decision to switch to a biosimilar [49].

\section{- Continued data collection}

As discussed above, the continued collection of clinical and savings-related data after marketing approval is important for increasing 


\begin{tabular}{|c|c|}
\hline Section of position paper & Key point \\
\hline \multirow[t]{2}{*}{ Introduction } & $\begin{array}{l}\text { "If properly developed clinically, manufactured to the correct standards and used appropriately (with } \\
\text { both the physician and patient being well-informed), [biosimilars] can positively impact the financial } \\
\text { sustainability of healthcare systems, globally" }\end{array}$ \\
\hline & $\begin{array}{l}\text { "To ensure that patients are being prescribed the safest and most efficacious treatment possible, all key } \\
\text { actors including the prescribers and patients, will need to understand the complexities of biosimilars and } \\
\text { take decisions that will be in the patient's interests" }\end{array}$ \\
\hline \multirow[t]{2}{*}{ Extrapolation } & $\begin{array}{l}\text { "As biosimilars are complex products that undergo new clinical studies in line with those of their reference } \\
\text { products, extrapolation of the indications should be permitted if verified scientifically" }\end{array}$ \\
\hline & $\begin{array}{l}\text { "Analytical, preclinical, pharmacokinetics, pharmacodynamics and clinical data, along with } \\
\text { immunogenicity, should be collected if the biosimilar is to be correctly extrapolated to all indications of its } \\
\text { reference product" }\end{array}$ \\
\hline \multirow[t]{3}{*}{$\begin{array}{l}\text { Clinical standards: safety and } \\
\text { efficacy of biosimilars }\end{array}$} & $\begin{array}{l}\text { "To appropriately capture clinical efficacy and immunogenic reactions, a biosimilar product should be } \\
\text { tested in the most sensitive populations and its data reported clearly" }\end{array}$ \\
\hline & "Once a biosimilar is on the market, continuous monitoring to ensure its safety and efficacy [is] required" \\
\hline & "Pharmacovigilance and Phase IV studies are essential" \\
\hline $\begin{array}{l}\text { Responsibilities between } \\
\text { prescribers and pharmacists }\end{array}$ & $\begin{array}{l}\text { "Prescribers should select the appropriate product based on sufficient data and knowledge and on } \\
\text { informing the patient of [any changes in product] (original biologic to biosimilar, biosimilar to original, } \\
\text { biosimilar to biosimilar)" }\end{array}$ \\
\hline \multirow[t]{2}{*}{ Conclusion } & $\begin{array}{l}\text { "With potential savings, a rapidly increasing range of biologic products and well-informed healthcare } \\
\text { professionals and patients, biosimilars represent one of the ways forward to obtain sustainability" }\end{array}$ \\
\hline & $\begin{array}{l}\text { "The manufacturing of biosimilars must adhere to the stringent regulations and guidelines stipulated by } \\
\text { the World Health Organization, European Medicines Agency and Food and Drug Administration" }\end{array}$ \\
\hline
\end{tabular}

stakeholders' knowledge of, and confidence in, a biosimilar. Prior to approval of CT-P13 in Europe, a pharmacovigilance program was proposed by the manufacturer and subsequently approved by the EMA [50]. This ongoing program includes new clinical trials, both in previously studied populations (e.g., patients with RA) and in populations for whom approval of CT-P13 is based on indication extrapolation (e.g., patients with IBD). For example, a randomized Phase III study was planned to compare the use of CT-P13 and reference infliximab in patients with active Crohn's disease. The first available data from this study, which showed that the efficacy and safety of CT-P13 and its reference product were similar up to week 6 of treatment, have recently been presented at a large European congress on IBD [51]. The European pharmacovigilance program for CT-P13 also includes postmarketing registries that are collecting data on the 'real-life' safety and efficacy of CT-P13 in patients in the clinic, including those with RA or IBD, up to the year 2026 [50].

Several physician-authored publications on the real-world use of CT-P13, especially in extrapolated IBD indications, have emerged in the literature since the approval of this biosimilar. Overall, real-world evidence collected about IBD confirms that CT-P13 shows good efficacy and tolerability in patients with Crohn's disease or ulcerative colitis, whether these patients are infliximab naive or switched from treatment with reference infliximab [52-56]. Determining whether switching from reference infliximab to CT-P13 had any impact on the efficacy, safety or immunogenicity of treatment was the aim of a Phase IV, randomized controlled trial that was sponsored by the Norwegian government (the NOR-SWITCH study). NOR-SWITCH recruited adult patients with $\mathrm{RA}$, spondyloarthritis, psoriatic arthritis, Crohn's disease, ulcerative colitis and psoriasis and found that, compared with maintenance on reference infliximab, 


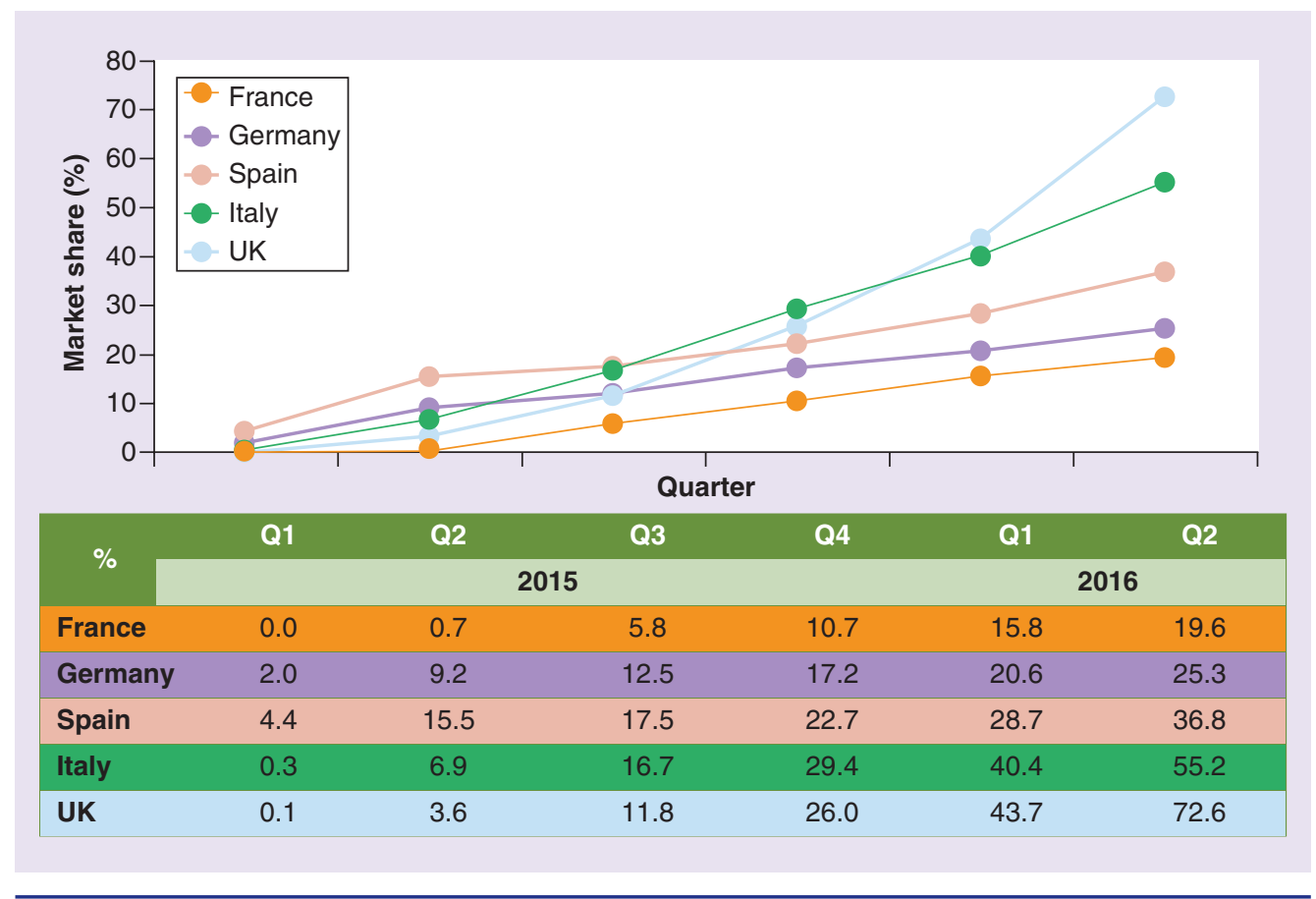

Figure 1. Infliximab market share of CT-P13 from January 2015 to the end of June 2016 in five European countries [40].

switching to CT-P13 from reference infliximab had no effect on the incidence of disease-worsening, adverse events or antidrug antibodies [57].

Since cost is the key factor encouraging the uptake of biosimilars, generation of data on projected and actual savings is to be encouraged. Budget impact analyses allow the prediction of potential cost savings following the introduction of a biosimilar into a particular region or country. For example, a 3-year prevalence-based budget analysis predicted total cost savings of $€ 8-17$ million after CT-P13 was introduced for the treatment of Crohn's disease in Bulgaria, Czech Republic, Hungary, Poland, Romania and Slovakia [58]. If such savings were redirected to allow treatment of other patients, an additional 722-1530 individuals could receive CT-P13 therapy. Real-world cost savings accrued for all approved indications across five European countries have also been calculated for CT-P13 [40]. Between January 2015 and June 2016, total cost savings associated with CT-P13 use in France, Germany, Italy, Spain and the UK amounted to $€ 32$ million, potentially enabling around 5400 new patients to access treatment (Table 3) [40]. An additional consideration, when predicting the pharmacoeconomic impact of biosimilar use, is the potential reduction in price of the reference product following the introduction of a biosimilar. This would reduce cost savings compared with the originator drug, but would still have a favorable budgetary impact overall.

\section{- Incorporation into treatment guidelines/ medical society recommendations}

With stakeholder perceptions about CT-P13 becoming more positive and use of this biosimilar in the clinic increasing, the accumulating evidence is beginning to influence treatment guidelines and medical society recommendations. For example, European League against Rheumatism guidelines for the management of RA include approved biosimilars alongside reference infliximab and other TNF inhibitors as recommended treatment options after methotrexate and/or conventional nonbiologic disease-modifying antirheumatic drugs have failed [59]. Notably, the European Crohn's and Colitis Organization (ECCO) has recently changed its position on the use of biosimilars in patients with IBD. From an initially cautious approach that stated, for example, that "efficacy in IBD cannot be predicted from effectiveness in other indications" [60], ECCO now takes a much more positive view toward biosimilars, acknowledging that "clinical studies of equivalence in the most sensitive indication can 
Table 3. Total cost savings between January 2015 and the end of June 2016, and the number of additional patients able to access biologic therapy for 1 year due to use of CT-P13 in five European countries.

\begin{tabular}{|lll|}
\hline France & Total cost savings $(€)$ & Number of additional patients \\
\hline Germany & 0 & 0 \\
\hline Italy & $2,791,405$ & 369 \\
\hline Spain & $9,958,223$ & 1699 \\
\hline UK & $12,233,004$ & 2222 \\
\hline Total & $7,453,488$ & 1138 \\
\hline Data taken from $[40]$. & $32,436,120$ & 5428 \\
\hline
\end{tabular}

provide the basis for extrapolation [and that] therefore data for the usage of biosimilars in IBD can be extrapolated from another sensitive indication" [61]. ECCO acknowledges that this shift has been driven not only by evidence from reallife studies of CT-P13 in IBD patients and the findings of the NOR-SWITCH trial but also by a better understanding of biosimilars and their developmental and approval pathways [61]. Some national medical societies have also recommended use of CT-P13. For example, the British Society of Gastroenterology has recently published guidance on the use of this biosimilar in IBD which states "there is sufficient data from observational studies to show that safety and clinical efficacy of CT-P13 are comparable to the originator drug, with similar immunogenicity" [62]. This stance contrasts with earlier guidance from the same society that urged caution on the use of anti-TNF biosimilars in IBD [63].

\section{Conclusion}

We are entering a new era in anticancer treatment that will see widespread use of biosimilar drugs in everyday practice. Approval of these agents is governed by strict regulatory requirements such that any biosimilar approved by the EMA or FDA will have undergone rigorous evaluations and comparisons with its reference product.

Although biosimilar clinical data may not be available for all approved indications of the reference product, experience with the first monoclonal antibody biosimilars (such as CT-P13 in rheumatology and gastroenterology) suggests that approved biosimilar oncology drugs will not be associated with unexpected clinical safety or efficacy concerns. Based on current understanding of healthcare provider's perceptions of biosimilars, together with learnings from the introduction of CT-P13, education to address information gaps, continued data collection and provision of relevant guidance from well-respected medical bodies will be key to stakeholders' acceptance of biosimilars, and to their safe and effective use in cancer treatment.

\section{Future perspective}

The constantly increasing costs of cancer care are unsustainable and can prevent some patients from receiving optimal treatment. As patents of many biologic anticancer drugs expire, significant growth in the use of biosimilars is predicted, offering an opportunity to help combat the rising costs of cancer treatment and increase the numbers of patients accessing biologic therapies. The recent approval of the rituximab biosimilar CT-P10 (Truxima) in Europe and South Korea signifies the beginning of a new era of biosimilar anticancer drug therapy. While stakeholders in cancer care currently appear to have mixed perceptions of biosimilars, primarily due to 'knowledge gaps,' experience with the biosimilar CT-P13 in other indications suggests that stakeholder acceptance can be achieved via education, continued data collection and provision of relevant guidance. A favorable shift in the perception of biosimilars has occurred recently in other fields, and a position paper from ESMO suggests that "with potential savings, a rapidly increasing range of biologic products and well-informed healthcare professionals and patients, biosimilars represent one of the ways forward to obtain sustainability." Biosimilars represent an exciting new chapter in cancer treatment that is predicted to evolve significantly over the coming years.

Financial \& competing interests disclosure WS Kim has received research funding from Kyowa Kirin, Johnson \& Johnson, CELLTRION, Roche and Novartis, and personal fees from Johnson \& Johnson, CELLTRION 
and Roche outside the submitted work. M Ogura has received research funding from Symbio, and personal fees from CELLTRION, Celgene, AstraZeneca, Takeda, Mundipharma, Jansen and Meiji Seika Pharma outside the submitted work. HC Kwon and D Choi are employees of CELLTRION Healthcare Co., Ltd. The authors have no other relevant affliations or financial involvement with any organization or entity with a financial interest in or financial conflict with the subject matter or materials discussed in the manuscript apart from those disclosed.

Writing assistance was utilized in the production of this manuscript. Medical writing support during the preparation of this article was provided by Rick Flemming, PhD, CMPP (Aspire Scientific, Bollington, UK) and was funded by CELLTRION Healthcare Co., Ltd (Incheon, Republic of Korea).

\section{EXECUTIVE SUMMARY}

\section{Background}

- As patents for biologic anticancer agents expire, significant growth in the use of biosimilars is predicted, offering an opportunity to lower the costs of cancer treatment and increase patient access to biologic therapies.

- If biosimilars are to be fully accepted and widely used in the clinic, it is important to understand the current perceptions and informational needs of key stakeholders in cancer treatment.

- Positive experience with CT-P13 (Remsima ${ }^{\circledR}$ and Inflectra ${ }^{\circledR}$ ), a biosimilar of the TNF inhibitor infliximab used to treat rheumatoid arthritis and other inflammatory disorders, provides guidance on how stakeholder perceptions can evolve to ensure the safe and effective use of biosimilars in cancer therapy.

\section{Current perceptions of biosimilars among cancer treatment stakeholders}

- Cost and the availability of efficacy and safety data are key factors that will drive the uptake of new biosimilars among physicians who care for patients with cancer; similarly, the lower cost of biosimilars makes these agents generally attractive to payers. Pharmacists may be influenced in their decision to substitute interchangeable biosimilars by the name of the product; nurses acknowledge their need for education relating to biosimilars; and awareness of biosimilars by patients, caregivers and the general public is low.

\section{Establishing biosimilar cancer therapeutics in clinical practice}

- To increase the uptake of biosimilars in clinical practice, the perceptions of some stakeholders will need to be challenged, and their educational and informational requirements addressed through a combination of appropriately targeted education, continued data collection following regulatory approval, and the provision of expert guidance.

\section{CT-P13: learnings from the first monoclonal antibody biosimilar}

- CT-P13 was the first biosimilar to be approved by the EMA for all indications held by reference infliximab. With growing uptake in many European countries, CT-P13 provides a useful case study to explore stakeholder acceptance of biosimilars.

\section{Conclusion}

- A new era in anticancer treatment will see widespread use of biosimilar drugs.

- Understanding healthcare provider perceptions of biosimilars, along with learnings from the introduction of CT-P13, will guide efforts to increase stakeholder confidence in these biosimilar cancer therapeutics, and to ensure their safe and effective use. 


\section{References}

Papers of special note have been highlighted as: - of interest; $\bullet \bullet$ of considerable interest

1 Calo-Fernandez B, Martinez-Hurtado JL. Biosimilars: company strategies to capture value from the biologics market. Pharmaceuticals 5(12), 1393-1408 (2012).

2 European Medicines Agency. European public assessment report for Truxima. www. ema.europa.eu/docs/en_GB/document_ library/EPAR__Summary_for_the_public/ human/004112/WC500222696.pdf

3 Schellekens H, Smolen JS, Dicato M, Rifkin RM. Safety and efficacy of biosimilars in oncology. Lancet Oncol. 17(11), e502-e509 (2016).

4 Buske C, Ogura M, Kwon HC, Yoon SW. An introduction to biosimilar cancer therapeutics: definitions, rationale for development and regulatory requirements. Future Oncol. 13(15s), 5-16 (2017).

5 European Medicines Agency. Procedural advice for users of the centralised procedure for generic/hybrid applications. www.ema. europa.eu/docs/en_GB/document_library/ Regulatory_and_procedural_ guideline/2009/10/WC500004018.pdf

6 European Medicines Agency. Guideline on the investigation of bioequivalence. www. ema.europa.eu/docs/en_GB/document_ library/Scientific_guideline/2010/01/ WC500070039.pdf

7 European Medicines Agency. Guideline on similar biological medicinal products containing biotechnology-derived proteins as active substance: non-clinical and clinical issues. www.ema.europa.eu/docs/en_GB/ document_library/Scientific_ guideline/2015/01/WC500180219.pdf

-• EMA guideline providing detailed information relating to the well-defined regulatory requirements for approval of a biosimilar, involving rigorous evaluations and comparisons with its reference product.

8 European Medicines Agency. Guideline on similar biological medicinal products containing biotechnology-derived proteins as active substance: quality issues (revision 1). www.ema.europa.eu/docs/en_GB/ document_library/Scientific_ guideline/2014/06/WC500167838.pdf

9 European Medicines Agency. Guideline on similar biological medicinal products containing monoclonal antibodies - nonclinical and clinical issues. www.ema.europa. eu/docs/en_GB/document_library/ Scientific_guideline/2012/06/ WC500128686.pdf
10 US Food and Drug Administration. Quality considerations in demonstrating biosimilarity of a therapeutic protein product to a reference product. Guidance for industry. www.fda. gov/downloads/drugs/guidances/ucm291134. pdf

11 US Food and Drug Administration. Scientific considerations in demonstrating biosimilarity to a reference product. Guidance for industry. www.fda.gov/downloads/drugs/guidances/ ucm291128.pdf

-• Current requirements of the US FDA in demonstrating biosimilarity to a reference product.

12 Baer II WH, Maini A, Jacobs I. Barriers to the access and use of rituximab in patients with non-Hodgkin's lymphoma and chronic lymphocytic leukemia: a physician survey. Pharmaceuticals 7, 530-544 (2014).

13 Lammers P, Criscitiello C, Curigliano G, Jacobs I. Barriers to the use of trastuzumab for HER 2+ breast cancer and the potential impact of biosimilars: a physician survey in the United States and emerging markets. Pharmaceuticals 7, 943-953 (2014).

14 Monk BJ, Lammers PE, Cartwright T, Jacobs I. Barriers to the access of bevacizumab in patients with solid tumors and the potential impact of biosimilars: a physician survey. Pharmaceuticals 10(19), 1-11 (2017).

15 Generics and Biosimilars Initiative. US doctors poised to prescribe biosimilars. http:// gabi-journal.net/news/us-doctors-poised-toprescribe-biosimilars

16 Cohen H, Beydoun D, Chien D et al. Awareness, knowledge and perceptions of biosimilars among specialty physicians. $A d v$. Ther. 33, 2160-2172 (2016).

- A recent US survey of physicians, including medical oncologists and hematologistoncologists, who regularly prescribe biologic drugs that identified five major 'knowledge gaps' to be addressed by evidence-based education on biosimilars.

17 Ogura M, Coiffier B, Kwon HC, Yoon SW Scientific rationale for extrapolation across cancer indications: case study of CT-P10. Future Oncol. 13(15s), 45-53 (2017).

18 Gewanter HL. Naming and labelling of biologicals - a survey of US physicians' perspectives. GaBI J. 6(1), 7-12 (2017).

19 Generics and Biosimilars Initiative. Survey highlights the importance of unique names for biosimilars. http://gabi-journal.net/news/ survey-highlights-the-importance-of-uniquenames-for-biosimilars

20 Dolinar RO, Reilly MS. Biosimilars naming, label transparency and authority of choice survey findings among European physicians. GaBI J. 3(2), 58-62 (2014).

21 European Medicines Agency. Questions and answers on biosimilar medicines (similar biological medicinal products). www.ema. europa.eu/docs/en_GB/document_library/ Medicine_QA/2009/12/WC500020062.pdf

22 Niazi SK. Appendix: glossary of terms. In: Biosimilars and Interchangeable Biologics: Tactical Elements. Niazi SK (Ed.). CRC Press, FL, USA, 507-561 (2015).

23 European Medicines Agency. Concept paper on extrapolation of efficacy and safety in medicine development. www.ema.europa.eu/ docs/en_GB/document_library/Scientific guideline/2013/04/WC500142358.pdf

24 European Medicines Agency. Procedural advice for users of the centralised procedure for similar biological medicinal products applications. www.ema.europa.eu/docs/en GB/document_library/Regulatory_and_ procedural_guideline/2012/04/ WC500125166.pdf

25 Tabernero J, Vyas M, Giuliani R et al. Biosimilars: a position paper of the European Society for Medical Oncology, with particular reference to oncology prescribers. ESMO Open 1(6), e000142 (2017).

- European Society for Medical Oncology position statement on biosimilars and issues in the field of oncology.

26 European Medicines Agency. Note for guidance on the investigation of bioavailability and bioequivalence. www.ema. europa.eu/docs/en_GB/document_library/ Scientific_guideline/2009/09/ WC500003519.pdf

27 Tomaszewski D. Biosimilar naming conventions: pharmacist perceptions and impact on confidence in dispensing biologics. J. Manag. Care Spec. Pharm. 22(8), 919-926 (2016).

28 Fernandez-Lopez S, Kazazz D, Bashir M, McLaughlin T. Assessment of pharmacists' views on biosimilar naming conventions. J. Manag. Care Spec. Pharm. 21(3), 188-195 (2015).

29 Rana JB, Chang DY. Pharmacist perception of biosimilar agents in the U.S. Pharmacy Purchas. Prod. 9(7), 8 (2012).

30 Schneider P, Reilly MS. Naming and labelling of biologicals - the perspective of hospital and retail pharmacists. GaBI J. 5(3), 151-155 (2016).

31 Kalbasko A, Spoors J. Biosimilar or different? Understanding the payer perspective. Value Health 19(7), A461-A462 (2016). 
32 Pinheiro VA, Buetas ZA, Storer M. Understanding the payer dilemma with biosimilar mAbs: striking the right balance between budget needs and patient outcomes. Value Health 17(7), A326-A327 (2014).

33 Amgen, Inc. Trends in biosimilars report. www.amgenbiotech.com/resources/2015 Trends_in_Biosimilars_Report-83531R1V1. pdf

34 US Food and Drug Administration. Considerations in demonstrating interchangeability with a reference product. www.fda.gov/downloads/Drugs/ GuidanceComplianceRegulatoryInformation/ Guidances/UCM537135.pdf

35 National Institute for Health and Care Excellence. NICE's biosimilars position statement. www.nice.org.uk/Media/Default/ About/what-we-do/NICE-guidance/ NICE-technology-appraisals/biosimilarsstatement.pdf

36 Zelenetz AD, Ahmed I, Braud EL et al. NCCN biosimilars white paper: regulatory, scientific, and patient safety perspectives. $J$. Natl Compr. Canc. Netw. 9(Suppl. 4), S1-S22 (2011).

37 Roe $\mathrm{H}$. The rise of biosimilars in cancer care. Br. J. Nurs. 24, S28-S29 (2015).

38 Jacobs I, Singh E, Sewell KL, Sabbagh AAL, Shane LG. Patient attitudes and understanding about biosimilars: an international cross-sectional survey. Patient Prefer. Adherence 10, 937-948 (2016).

39 Generics and Biosimilars Initiative. Elderly patients in US lack knowledge on biosimilars. http://gabi-journal.net/news/elderly-patientsin-us-lack-knowledge-on-biosimilars

40 Han S, Kim S, Kim J et al. The pharmacoeconomic impact of biosimilar infliximab (CT-P13) in Europe from January 2015 to June 2016. Presented at: 12th Congress of the European Crohn's and Colitis Organisation. Barcelona, Spain, 15-18 February 2017 (Abstract P582).

-• Real-world data on cost savings with CT-P13 across five European countries between January 2015 and June 2016, and estimated additional number of patients with access to treatment.

41 Danese S, Fiorino G, Michetti P. Changes in biosimilar knowledge among European Crohn's Colitis Organization (ECCO) members: an updated survey. J. Crohns Colitis 10(11), 1362-1365 (2016).

42 Park W, Hrycaj P, Jeka S et al. A randomised, double-blind, multicentre, parallel-group, prospective study comparing the pharmacokinetics, safety, and efficacy of
CT-P13 and innovator infliximab in patients with ankylosing spondylitis: the PLANETAS study. Ann. Rheum. Dis. 72(10), 1605-1612 (2013).

43 Park W, Yoo DH, Jaworski J et al. Comparable long-term efficacy, as assessed by patient-reported outcomes, safety and pharmacokinetics, of CT-P13 and reference infliximab in patients with ankylosing spondylitis: 54-week results from the randomized, parallel-group PLANETAS study. Arthritis Res. Ther. 18(1), 25 (2016).

44 Park W, Yoo DH, Miranda P et al. Efficacy and safety of switching from reference infliximab to CT-P13 compared with maintenance of CT-P13 in ankylosing spondylitis: 102-week data from the PLANETAS extension study. Ann. Rheum. Dis. 76(2), 346-354 (2017).

45 Yoo DH, Hrycaj P, Miranda P et al. A randomised, double-blind, parallel-group study to demonstrate equivalence in efficacy and safety of CT-P13 compared with innovator infliximab when coadministered with methotrexate in patients with active rheumatoid arthritis: the PLANETRA study. Ann. Rheum. Dis. 72(10), 1613-1620 (2013).

46 Yoo DH, Prodanovic N, Jaworski J et al. Efficacy and safety of CT-P13 (biosimilar infliximab) in patients with rheumatoid arthritis: comparison between switching from reference infliximab to CT-P13 and continuing CT-P13 in the PLANETRA extension study. Ann. Rheum. Dis. 76(2), 355-363 (2017).

- Open-label extension of the Phase III PLANETRA study of CT-P13 compared with reference infliximab in rheumatoid arthritis, indicating comparable efficacy and tolerability in patients who switched from reference product to CT-P13 for an additional year and in those who had long-term CT-P13 treatment for 2 years.

47 Yoo DH, Racewicz A, Brzezicki J et al. A phase III randomized study to evaluate the efficacy and safety of CT-P13 compared with reference infliximab in patients with active rheumatoid arthritis: 54-week results from the PLANETRA study. Arthritis Res. Ther. 18(1), 82 (2016).

- Phase III PLANETRA study of CT-P13 compared with reference infliximab in rheumatoid arthritis, indicating comparable efficacy, safety, immunogenicity and pharmacokinetics/pharmacodynamics at 54 weeks.

48 Global Alliance for Patient Access. Advocating for a healthier world. http://gafpa.org/
49 National Rheumatoid Arthritis Society. NRAS position paper on biosimilar medicines. www.nras.org.uk/data/files/Publications/ NRAS\%20Revised\%20position $\% 20$ paper\%20Final\%206.6.16.pdf

50 European Medicines Agency. Committee for Medicinal Products for Human Use (CHMP). Assessment report: Remsima. EMEA/H/C/002576/0000.

www.ema.europa.eu/docs/en_GB/ document_library/EPAR_-_Public_ assessment_report/human/002576/ WC500151486.pdf

51 Kim YH, Ye BD, Pesegova M et al. Phase III randomised, double-blind, controlled trial to compare biosimilar infliximab (CT-P13) with innovator infliximab in patients with active Crohn's disease: early efficacy and safety results. Presented at: 12th Congress of the European Crohn's and Colitis Organisation. Barcelona, Spain, 15-18 February 2017 (Abstract DOP061).

52 Fiorino G, Manetti N, Armuzzi A et al. The PROSIT-BIO cohort: a prospective observational study of patients with inflammatory bowel disease treated with infliximab biosimilar. Inflamm. Bowel Dis. 23(2), 233-243 (2017).

53 Jahnsen J, Kaasen Jorgensen K. Experience with biosimilar infliximab $\left(\right.$ Remsima $\left.^{\circledR}\right)$ in Norway. Dig. Dis. 35(1-2), 83-90 (2017).

54 Kolar M, Duricova D, Bortlik M et al. Infliximab biosimilar (Remsima) in therapy of inflammatory bowel diseases patients: experience from one tertiary inflammatory bowel diseases centre. Dig. Dis. 35(1-2), 91-100 (2017).

55 Razanskaite V, Bettey M, Downey L et al. Biosimilar infliximab in inflammatory bowel disease: outcomes of a managed switching programme. J. Crohns Colitis doi:10.1093/ ecco-jcc/jjw216 (2017) (Epub ahead of print).

56 Vegh Z, Kurti Z, Lakatos PL. Real-life efficacy, immunogenicity and safety of biosimilar infliximab. Dig. Dis. 35(1-2), 101-106 (2017).

57 Goll GL, Olsen IC, Jorgenson KK et al. Biosimilar infliximab (CT-P13) is not inferior to originator infliximab: results from a 52-week randomized switch trial in Norway. Arthritis Rheumatol. 68(Suppl. 10), Abstract 19L (2016).

58 Brodsky V, Rencz F, Pentek M, Baji P, Lakatos PL, Gulacsi L. A budget impact model for biosimilar infliximab in Crohn's disease in Bulgaria, the Czech Republic, Hungary, Poland, Romania and Slovakia. Expert Rev. Pharmacoecon. Outcomes Res. 16(1), 119-125 (2016). 
59 Smolen JS, Landewe R, Breedveld FC et al. EULAR recommendations for the management of rheumatoid arthritis with synthetic and biological disease-modifying antirheumatic drugs: 2013 update. Ann. Rheum. Dis. 73, 492-509 (2014).

60 Danese S, Gomollon F, Governing Board and Operational Board of ECCO. ECCO position statement: the use of biosimilar medicines in the treatment of inflammatory bowel disease (IBD). J. Crohns Colitis 7(7), 586-589 (2013).
61 Danese S, Fiorino G, Raine T et al. ECCO position statement on the use of biosimilars for inflammatory bowel disease: an update. $J$. Crohns Colitis 11(1), 26-34 (2017).

- European Crohn's and Colitis Organisation position statement that indicates a changing attitude toward the use of biosimilars in patients with inflammatory bowel disease, from an initially cautious approach to a far more positive view.
62 British Society of Gastroenterology. BSG guidance on the use of biosimilar infliximab CT-P13 in IBD. www.bsg.org.uk/clinical-guidance/ibd/ bsg-guidance-on-the-use-of-biosimilarinfliximab-ct-p13-in-ibd.html

63 British Society of Gastroenterology. IBD Section statement on biosimilar drugs. www.bsg.org.uk/images/stories/docs/clinical/ guidance/biosimilars_final2014.pdf 
